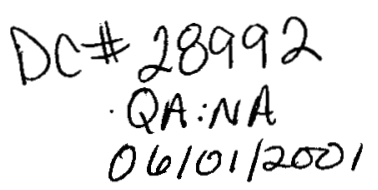

\title{
Temperature Effects on Seepage Fluid Compositions at Yucca Mountain
}

Nicolas Spycher and Eric Sonnenthal

MOL . 20010808.0254

Contact: Nicolas Spycher, (510) 495-2388, nspycher@lbl.gov

\section{Research Objectives}

This project investigated the effect of two repository operating temperature modes on coupled thermal, hydrological, and chemical processes around potential nuclear wasteemplacement tunnels (drifts) at Yucca Mountain, Nevada. The main objective of this study was to evaluate the composition of fluids (water and gas) that could enter the drifts, because these data directly relate to the performance of waste canisters and other in-drift engineered systems over the life of the potential repository.

\section{Approach}

Multicomponent reactive transport simulations were performed using TOUGHREACT, initially written by $\mathrm{T}$. Xu and $\mathrm{K}$. Pruess at LBNL and modified here to handle hightemperature and boiling environments. Two repository operating temperature modes were investigated: (1) a "high-temperature" mode, which considered a short preclosure ventilation period (50 years) and gave rise to above-boiling temperatures in rocks around the drift for hundreds of years, and (2) a "low-temperature" mode with a smaller heat load and longer preclosure ventilation (300 years), yielding temperatures at the surface of the waste package below $85^{\circ} \mathrm{C}$ (a design threshold) and thus below boiling conditions. Simulations under ambient conditions (no heat load) were also conducted to serve as a baseline for comparing results of thermal-loading simulations.

\section{Accomplishments}

For each considered temperature mode, time profiles of various calculated thermal, hydrological and chemical parameters were generated for several locations around a simulated drift (Figure 1). In the high-temperature case, fractures around the drift dry out as soon as preclosure ventilation ends and remain dry until approximately 1,500 years. During this time period, carbon dioxide concentrations (pore gas) fall below ambient values because of boiling and displacement by steam. In contrast, in the low-temperature case, fractures never dry out and carbon dioxide concentrations remain above ambient values because this gas is exsolved from matrix pore waters (by heating) and transported into fractures. For most major cations and anions, predicted concentrations immediately after dryout in the high-temperature case are significantly higher (one or more orders of magnitude) than in the low-temperature case, because of larger prior evaporative concentration. However, this effect dissipates relatively quickly as percolating waters rewet the drift wall after dryout.

\section{Significance of Findings}

During the first simulated 5,000 years or so, seepage water compositions around drifts are more affected by high than low temperatures, primarily as a result of evaporative concentration. However, at temperatures below boiling, the continuous presence of water in fractures around the drift increases the potential for seepage to occur. In the long term 
(5,000 years or more), water and gas compositions return to ambient values along with temperatures and become largely dominated by the composition of infiltrating water, regardless of the operating temperature mode of the repository. Therefore, the variability of infiltrating water compositions is also important in determining the variability of fluid compositions that could enter drifts.

\section{Related Publications}

Spycher N. and E. Sonnenthal, Section 6.3.1 in Supplemental Science and Performance Analyses, Volume 1, Scientific Bases and Analyses, TDR-MGR-MD-000007 Vol. 1

REV 00D (Draft), Las Vegas, Nevada: Bechtel SAIC Company, 2001.

\section{Acknowledgments}

This work was supported by the Director, Office of Civilian Radioactive Waste Management, U.S. Department of Energy, through Memorandum Purchase Order EA9013MC5X between Bechtel SAIC Company, LLC and the Ernest Orlando Lawrence Berkeley National Laboratory (Berkeley Lab). The support is provided to Berkeley Lab through the U.S. Department of Energy Contract No. DE-AC03-76SF00098.

Figure 1. Predicted time profiles of thermal, hydrologic, and chemical parameters at the drift crown in fractures. The model infiltration rate was increased at 600 years and 2,000 years to account for possible future climate changes. 


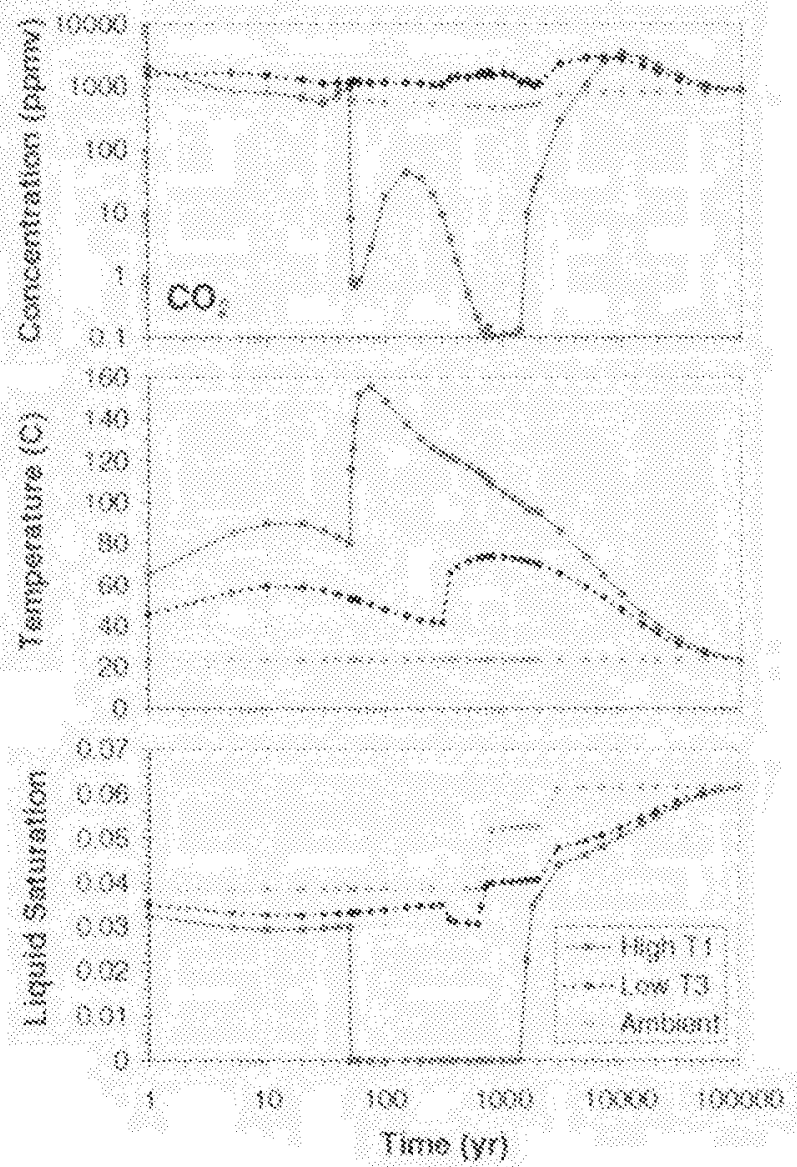

